\title{
Experiences of children with autism spectrum disorders in adapted physical education
}

\author{
Josephine Blagrave \\ Department of Kinesiology, California State Univesity, Chico, USA
}

School-age children with autism spectrum disorder (ASD) are rarely asked to describe their experiences within
the programs that they receive and are largely missing from the narrative of their own lives. Current literature
on the experiences of children with ASD have focused on special education classrooms, sensory perceptions, and
general physical education classes and no prior studies have addressed how middle school-age children with ASD
perceive their adapted physical education (APE) experience. Data were collected from participants $(N=10)$ through
a drawing, an observation in their APE setting, and an interview. Themes identified were enjoyment in participation,
the influence of peers and family members in participation, and the sensory experience of APE. Children with ASD
were able to communicate their experiences in adapted physical education settings services and the barriers and
facilitators that exist both in class instruction and transfer of the skills learned into everyday movement experiences.

Keywords: first-hand accounts, barriers, facilitators

\section{Introduction}

Autism spectrum disorder (ASD) is a developmental disability that affects 1 of every 68 children in the United States (Centers for Disease Control and Prevention [CDC], 2015). Children with ASD have deficits in their communication and social interactions and tend to demonstrate repetitive and restrictive behaviors (American Psychiatric Association, 2013). Though motor skills are not part of the diagnostic criteria for ASD, studies have indicated that individuals with ASD frequently exhibit deficits in their gross motor (Cook, Blackmore, \& Press, 2013) and object control (Libertus, Shepard, Ross, \& Landa, 2014; Schurink, Hartman, Scherder, Houwen, \& Visscher, 2012; Whyatt \& Craig, 2013) skills. Physical education (PE) is one school setting in which children with ASD can improve their current level of motor performance as well as gain new skills. Researchers often ask teachers, parents and instructional aids about their experiences with teaching students with ASD but not the individuals themselves (Carter et al., 2014; Schultz, Sreckovic, Able, \& White, 2016; Syriopoulou-Delli, Cassimos \& Polychronopoulou, 2016). This is one way to examine the how individuals with ASD perceive an experience. However, it is one sided and eliminates the first-hand account, thereby leaving out the voice of the individuals themselves. Limited studies have examined how children with ASD view their school experience - whether it is inclusion (placements in a typical classroom) or a specialized service [such as adapted physical education (APE)]. Humphrey and Lewis (2008) examined how high-functioning children with ASD in the United Kingdom viewed their inclusion experience using semi-structured interviews, drawings, and journaling. Students were able to effectively communicate their experiences through these three data-collection methods, and themes of isolation, loneliness, and a feeling of difference were expressed. To date, one study has examined the perspective of children with ASD in PE (Healy, Msetfi, \& Gallagher, 2013). In this study, 12 children with ASD who were receiving PE services were interviewed in focus groups and shared themes of individual challenges, peer interactions and exclusion.

Middle school children with ASD frequently participate in APE. Though they are capable of communicating their experiences and helping to inform research that could lead to changes in curriculum or how teachers perceive their experiences, no previous studies have captured their perspectives regarding these services. Recent research initiatives have asked for individuals with autism of all ages to be included as active stakeholders in the research surrounding their disability so that their voices are heard (Grinker, 2015; Robison, 2015; Solomon, 2015). Although researchers can speculate what barriers might or might not exist for middle school children with ASD in APE services, asking the participants to report on 
their experience is an underutilized method in studies of children with ASD and until that is done, the experience of these individuals cannot be fully understood.

To examine these barriers and facilitators that may exist for this population, a socioecological model was used. The socioecological model aims to identify the internal and external forces that affect individuals in their health experiences (Bronfenbrenner, 1977). This model has been described as well suited for explaining engagement in physical activity behaviors and the multiple factors that influence those behaviors (Ding, 2004). According to this model, barriers to and facilitators of participation and activity fall into five types (Gyurcsik, Spink, Bray, Chad, \& Kwan, 2006):

a) interpersonal barriers, which can be attitudes and behaviors of the individual;

b) institutional barriers, such as the school or organization;

c) community barriers;

d) public policy barriers;

e) physical barriers.

Prior to the development of ecological models, researchers used intrapersonal factors to assign blame, responsibility, or success to individuals regarding their participation or nonparticipation in a social problem (Bronfenbrenner, 1977).

The socioecological model has been used in studies to examine barriers to and facilitators of afterschool activity participation in individuals with ASD (Obrusnikova \& Cavalier, 2011). Gyurcsik et al. (2006) used this model to explain the physical activity characteristics of children with disabilities. Socioecological factors that are both internal (intrapersonal) and external (interpersonal factors, institutional factors, community factors, and public policy and physical environment factors) are important to consider when reflecting on programming outcomes. Identifying the barriers to or facilitators of a given experience can inform the tailoring of interventions to help address concerns and improve experiences for individuals from all backgrounds.

The purpose of this study was to understand the experience of middle school children with ASD (ages 10-14) receiving APE. Historically, this population has been perceived as unable to communicate personal feelings because of their perceived inability to assign meaning to abstract concepts (Kana, Libero, Hu, Deshpande, \& Colburn, 2014; Loukusa, Mäkinen, Kuusikko-Gauffin, Ebeling, \& Moilanen, 2014; Moran et al., 2011). However, growing bodies of biographical literature (Fleischmann, 2012; Grandin,
2011; Higashida, 2013; Prince-Hughes, 2004; Robison, 2008; Tammet, 2007; Williams, 2007) and scientific research (Huws \& Jones, 2008) have suggested this might not be the case. To this end, the main research question explored in this study was: what are the feelings and perceptions of middle school children with ASD regarding APE experiences from their perspective?

\section{Method}

\section{Research Design}

Limited research has examined the experiences of children with ASD in a PE setting. In order to understand the experience of these individuals in this study, a phenomenological approach was used. Phenomenology aims to examine a shared experience of participants in a given phenomenon as well as the meaning that the participants' attribute to the measured experience (Hammersley, 2004). Three types of data were collected to gain a depth to their experience: a drawing about the participant's experience in APE as a whole, one observation by the primary investigator (PI) of the child in their APE setting, and one semi-structured interview. These data were collected over a two-week time frame. The data were then analyzed to determine themes related to the experiences of middle school children's experiences in APE and the use of these skills in other settings. Parental consent, participant assent, and expressive language level were obtained from all participants prior to data collection per University Institutional Review Board requirements.

\section{Recruitment}

A purposeful sample was used to recruit the participants needed for this study because of the limited focus on only children with ASD who receive APE services. Fliers regarding information for the study were sent home to the prospective participants who were identified by the APE teachers at area schools, and parents contacted the PI if they were interested in learning more about the study. The selection criteria for the study included

a) a current diagnosis of ASD by a qualified professional, and verification of the ASD diagnosis by the child's parents;

b) current attendance at a middle school in the selected school district;

c) ability to communicate verbally;

d) and current receipt of APE service.

The PI then worked with the family to set a schedule, during which, over the course of a 2-week period, 
the student was asked to draw one picture about their experiences in their APE class, be observed one time in their APE class, and then be interviewed about their overall experiences receiving APE services.

\section{Research Site/Participants}

This study occurred in a rural town in northern California in both the participant's APE school setting (observation) and in the participant's home (drawing and semi-structured interview). Diagnosis and placement for PE services were confirmed by both the APE professionals that work with the children as part of their caseload and their parents. APE services for this study were classified in two ways:

a) direct service,

b) consultation service.

Participants who received direct service $(n=7)$ worked in a setting with only an APE teacher and a paraprofessional to receive $\mathrm{PE}$ instruction. Participants who received consult $(n=3)$ participated in a general education setting with an APE teacher consulting for support as needed. The ten participants who enrolled in the study demonstrated narrative abilities of at least second-grade level, as indicated on their results of the conversation with the PI and by their score on the Test of Narrative Retell (TNR) - Second Grade (Spencer \& Pearson, 2012) screening tool. The TNR is a developmental language-screening tool used by professionals to assess narrative retell capabilities of children with communication difficulties. For this study, and the content being discussed, the PI confirmed with speech and language pathologists that a TNR screening of grade level two, as either "no additional support" or "some additional support" needed would adequately capture the responses of the interview questions by the participants. All participants in this study scored within this range. Table 1 provides more information about participant demographics.

\section{Data Collection Tools}

\section{Drawing}

In the present study, a prompted drawing by the participants was the first data gathered from the participants to provide a talking point throughout the rest of the study with the participant, to see if the participant described feelings regarding APE matched their drawing, and finally to complement the interview and observation data. All participants were given the same prompt "draw me a picture of what your APE class with teacher __ is like for you". Participants were provided with a blank piece of paper and a variety of writing and drawing implements to choose from: pens, colored pencils, markers, crayons and a pen and pencil.

The drawing took place during the initial meeting, following the administration of the TNR. Participants were provided with a blank sheet of paper, markers, crayons and colored pencils while seated at a table and then given the prompt: "draw me a picture of what your APE class with teacher ___ is like for you". Following the drawing prompt, participants were asked to explain their drawing. The PI prompted the participant to discuss components of their picture such as what an object was, what was happening or who was in it, if a component of the drawing was omitted. The interviews were audio recorded and then transcribed.

Table 1

Participant Demographics

\begin{tabular}{ccclcc}
\hline Participant & Gender & Age & \multicolumn{1}{c}{ TNR Range } & APE Service \\
\hline 1 & Male & 12 & No additional language support & Consult service \\
2 & Male & 14 & No additional language support & Direct service & Consult service \\
3 & Male & 10 & No additional language support & Direct service \\
4 & Female & 14 & No additional language support & Direct service \\
5 & Male & 11 & Supplemental language support & Direct service \\
6 & Male & 11 & Supplemental language support & Consult service \\
9 & Male & 11 & No additional language support & Direct service & Direct service \\
10 & Male & 14 & No additional language support & Supplemental language support &
\end{tabular}

Note. $\quad \mathrm{TNR}=$ Test of Narrative Retell; APE $=$ adapted physical education. 


\section{Observation}

Observation of activity by the researcher is a means of collecting data on what a participant is doing within a setting. This is described by Pitney and Parker (2009) as non-participatory in nature and to document activities of the participant as they occur. Direct observation is used in an ecological approach because it allows the researcher to take into account environmental factors that could be an influence (McKenzie, 2002). For this study, the observation sheet was divided into 1-minute increments and had categories for both direct observations of what was physically occurring as well as a second ("other") category to make notes of behavior, environment or other subjective remarks. Coding took place from the time the child was pulled out for APE (direct service) or began their PE setting with support (consult) and lasted for 20 minutes. APE teachers were asked if the sampled time was an accurate representation of a typical service time, and for all the participants the answer was yes.

Direct observation was used for each participant during one of his or her APE classes. The observations were done in a manner so as to not disrupt or draw attention to the student while participating in the service. This observation took place from the time the participant arrived for the APE service until the time he or she returned to the classroom placement. This descriptive observation was broken into one minute increments for the duration of the time the child is in APE and had two categories for each minute - one that describes the activity that the child was participating in and a second category that is subjective and documents behaviors or other occurrences that the PI thought should be noted.

\section{Semi-Structured Interview}

Semi-structured interview questions were developed based on current gaps of knowledge in ASD and APE research targeted in this study. The semi-structured interview questions consisted of four initial rapportbuilding questions that were straightforward and that the participants could answer confidently, followed by 14 open-ended questions that were specific to their experiences within the APE setting. The aim of these questions was to gain a rich understanding of how the participants perceived the services they were receiving and if these services supported/translated into activity on the playground at recess, or at home with family and peers. These research questions were reviewed by three professionals in higher education who had experience using qualitative research methods, interviewing individuals with disabilities, and working with children with ASD for both content validity and credibility of the interview questions in answering the research questions. The interview questions are shown below:

Q1. Where do you go to school?

Q2. What kinds of things do you like to do in your free time?

Q3. When you are at school, what is your favorite class?

Q4. Why is this your favorite class?

Q5. How often do you go to APE with (teacher name here)?

Q6. When you go to APE, how does it make you feel?

Q7. What kinds of activities do you do in APE?

Q8. How do you feel when you do each of those activities? For example, does it make your body feel good or stressed? Is it easy or hard?

Q9. Your APE teacher gave me a list of activities that you do in in APE. Please listen to the list as I read it to you. Tell me how you feel about each of these activities? (Read the child the list.)

Q10. If you could go to APE as much or as little as you wanted, how often would you go?

If no answer or unsure, provide prompt: For example, would you never go, sometimes go, go the same amount you currently go now, or go every day?

Q11. If you could do any activity all the time in APE, what activity would you choose? Why did you choose this activity?

Q12. Do you play any activities that you learn in APE at recess? If answer is Yes: Can you please tell me more-who do you play with? What do you like about it? If answer is No: Why do you not play activities that you learn in APE at recess?

Q13. Do you play any activities that you learn in APE at home with family or friends? If answer is Yes: Can you please tell me more - who do you play with? What do you like about it? If answer is No: Why do you not play activities that you learn in APE at home with family or friends?

Q14. Are there any activities you wish you could learn in APE that you haven't yet?

Q15. If you could change anything about your APE class, what would you change and why?

Q16. If you could be the APE teacher, what would you do with your student? 
Q17. The reason you are in APE classes is so that you can be more physically active for the rest of your life. Do you think this is important for your body? Why do you think that?

Q18. Is there anything else good or bad that you want to share with me about what being in APE is like for you?

Each participant was interviewed in their home at a time arranged by the family after their observation in the schools occurred. Interview times varied in length from 15-25 minutes depending on the depth of the response from the participant. Interview questions were followed in the same order for each subject. Participants were offered the option to read the interview questions before being formally asked to alleviate anxiety. All participants took the questions to look at them but did not comment until they were asked about them formally.

\section{Data Analysis}

The participants' drawings were analyzed using the methods described by Kalvaitis and Monhardt (2012). First, a coding taxonomy was created by noting all the items within the picture, until the list was exhaustive. Then the narrative of the picture was examined that was given by the child next to the picture and the taxonomy of the items in the picture. Items were then interpreted in the drawings, categorizing the picture's items as one of three categories: negative, positive, or neutral. Negative items were identified as items that were

a) described by the child as such in their interview transcripts or

b) show an obvious cultural identification of negativity such as a sad face or crossed out image.

Positive items were identified as items that were

a) described by the child as such in their interview transcripts or

b) showed an obvious cultural identification of positivity such as a smiley face.

Items designated as neutral

a) were not mentioned by the child in their interview transcript and

b) did not have culturally identifying information that might place them into a positive or negative category.

The categorization of these items by both the participant and PI helped to add insight to the overall perception of the child's APE experience.
Interviews were transcribed verbatim for each participant. First, each transcript was read multiple times to become familiar with the whole interview. Data analysis was coded in a first-cycle coding method, looking for elemental, affective, and exploratory subcategories as described by Miles, Huberman and Saldana (2013). Second-level coding was then conducted to explore themes within each participants experience, and for a shared experience between the participants. From these themes, there was then overall interpretation of the participants' experiences. Observations were coded for type of activity as well as the participants' behavior during their time in APE. Codes for type of activity were first described as specific movements and then generalized into broader movement categories: object control skills, gross motor skills, physical fitness, and game play. Behavior activities were coded for on or off task and for observable comments about their demeanor while in APE. The data were reviewed to determine whether the participants' reports of their actions in class were accurate and whether their feelings about their experience seemed represented in the observation. An example discrepancy would be if a child described being happy in APE but did not want to participate when observed. There were no discrepancies between the drawings and the observations for any of the participants.

Initially the data for each participant was treated as an individual data set. First larger segments of information were highlighted through each of the transcripts in response to the semi-structured interview questions because they offered the most insight into participants' experiences in APE. These sets were then examined for categories of information within these blocks of data. Pictures were coded for type of activity, subjects, and objects in the picture, as well as any narrative that the participant portrayed that might have been meaningful. Finally, observation notes were coded for activities and behaviors that occurred. After examining each type of data separately, the data were looked at as a whole for each participant. From the themes of these three data sets for each participant (the drawing, observation, and semi-structured interview), the data were examined for themes that occurred between participants to identify overarching themes in their shared experiences.

In qualitative studies, credibility, transferability, dependability, and conformability are used ensure validity and reliability. Credibility was verified by triangulating the data between the modes of data collection (interview, observation, and drawings). The data were also triangulated between the participants by 
reading each participant's data set individually and then comparing it against the data set of other participants (Smith, Flowers, \& Larkkin, 2009). Interviews were carried out until saturation of the questions is achieved. Member checks were also used to ensure validity by having participants examine the transcripts of their interviews and the interpretation of the themes presented. Member checking has been used as a successful method of ensuring validity in studies that have children (Thomas \& Magilvy, 2011). This method ensures collaborative coding as well as "provides ownership to the stakeholders and investment in the subsequent recommendations for social change" (Saldana, 2013, p. 34). Trustworthiness was achieved by verbatim transcription of the interviews, including pauses in the participant's language and filler words, such as uh or um. Participants were also asked to review their transcript to ensure that it accurately reflects what they were trying to say. Transferability was achieved by using thick descriptions of the participants in their own words and in addition to my analysis so that the reader could judge my findings. Dependability was achieved first by ensuring that the research questions in this study are addressed by the data that were collected. Furthermore, organizing data for coherence from the themes identified in the original transcription through the final write-up ensured that, if there was an audit, the data could be checked through my paper trail of raw data, notes, and final analysis. To demonstrate conformability in the study, detailed notes were kept, as well as raw data, drafts, and journals.

\section{Results}

Participants discussed their experiences in APE, and three themes were identified as a shared experience: enjoyment in participation, the influence of peers and family members in participation, and the sensory experience of APE.

\section{Enjoyment in Participation}

Participants shared positive sentiments of both their APE experience and physical activity, and all participants reported some positive aspect of their time in APE. Participant 1 commented that, "It makes me feel good to get exercise, it makes me feel glad." Participants showed smiles and gave their APE teacher high fives when they arrived to take them to APE, smiled throughout their time in APE, and had positive comments during their observations such as "I love basketball" (participant 5) or "this is really great" (participant 6). Participant 7 commented directly about the activities, describing class as, "a good thing" because "sometimes the games can be really fun. Because like, you know you can really do some fun stuff." Echoing the sentiments of Healy and Msetfi (2013), participant 3 shared that APE made him feel "exhausted but happy." One interesting comment from participant 5 that could also be characterized as a sensory feeling, was, "It (APE) makes me feel heavy. It's a good feeling." He could not describe what he was talking about more in depth, other than the heavy feeling good. Participant 8 enjoyed the health benefits of APE: “[APE] makes me feel like I'm losing weight. I want to go most of the time because I want to lose weight."

All participants spoke positively about their APE teachers and the paraprofessionals who were helping facilitate interactions with the participants who were receiving consult for their APE services. The participants all smiled when asked about their APE teachers during the semi-structured interviews as well as The APE teachers in the present study all knew the participants well and commented on both personal and school-related information about them. The teachers frequently joked and shared ideas and thoughts with the children, and the children reciprocated in kind.

Of the participants who drew pictures that included figures, none drew sad faces or symbols that would indicate a negative experience, and these children did not describe the pictures as negative, either. Participants $1,3,4,6,8,9$, and 10 all drew figures in their pictures that were smiling. The pictures for the participants 1 and 4 can be seen. Most participants drew pictures in which the people in them were smiling while participating in a physically active experience. In some pictures, it was evident that physical activity was occurring, such as in the drawings (see Figures 1 and Figures 2).

\section{Influence of Peers and Family Members}

Peers were seen as both a positive influence and a negative influence. Recess was an area most expressed by participants as having a positive and negative impact on using the motor skills that they had learned in APE in other settings. Participant 2 shared that he played basketball with his friend at recess. Participant 3 shared that he had "no friends" and "was forever alone" at recess and that is why he doesn't use any of the skills he has learned in APE at recess. Participant 7 said he played both basketball and four square at recess "a little bit". When asked who he played with, 


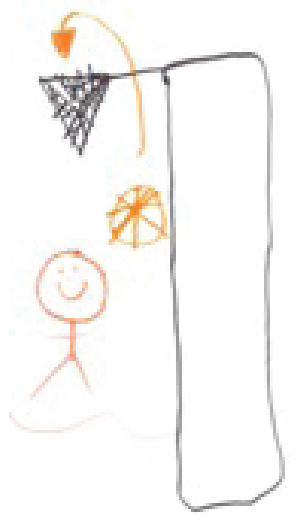

Figure 1. Drawing by participant 1

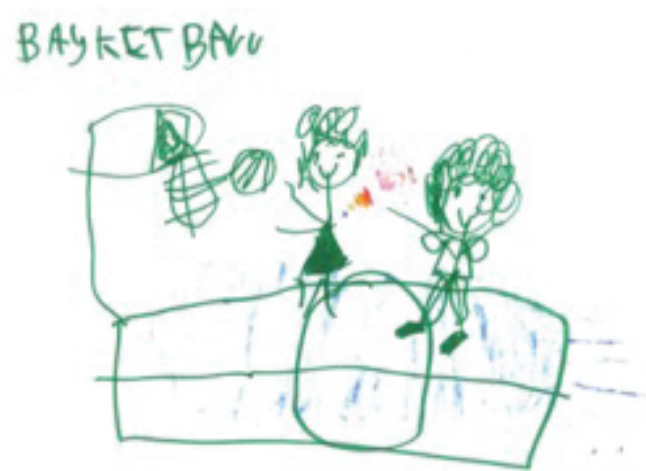

Figure 2. Drawing by participant 4

he said, "just other kids". He went on to say, "I kinda wish that... I kinda wish that sometimes teammates will not always be taunting. Because I've had that problem, it'll happen a lot. Because let's say like I want something, sometimes your teammate may be a bit taunting and just taunt stuff." Participant 7 looked down and was silent for 5-7 seconds after sharing this.

Family members in this study were seen as an influence in a variety of ways. Participant 4 was very excited to swim in her pool with her family (and was also reflected in a drawing) and said that her dad said physical activity was "important because it helps you live longer." Participant 6 practiced dribbling skills at home with his parents and brother and said that it "was really fun". Participant 7 shared that though he had a basketball and basketball hoop at home, they "hadn't touched it in years." Participant 10 had both a basketball hoop and tetherball at his house and shared that he played both with his family: "I love playing bowling with my brothers! I play basketball with friends, baseball on a team."

\section{Sensory Experience of APE}

Participants shared that, during APE, they feel too hot, sweat too much, and wish to be cooler. Participant 2 commented that APE "Makes me so sweaty I need to go get a drink of water. It makes me hungry as well." Participant 4 complained about the heat but had a way to fix it, suggesting, "I would want to change running so that we can run laps in the sprinklers." Similar comments were heard from participant 9 and participant 7 who participated in their APE time willingly, but also complained about being too hot and needed water breaks. It is important to note that though it was spring in Northern California, the temperatures during the month of data collection were between 70-80 degrees Fahrenheit and all of the observations were done before noon. Conversely, some participants shared positive aspects of APE. Participant 6 reported that it fulfills a sensory need by making him feel heavy (he described this as a positive feeling). Participant 1 viewed APE as a break on his eyes from the florescent lights saying, "It makes me feel good to get come exercise. No they don't [hurt from APE]. I think it's from the florescent lights [in the classroom]."

Throughout the observation process, participants experienced many distractions due to the open nature of the classes. Of the 10 participants, 6 had their APE held outside, on a blacktop, where the following distractions were observed: air temperature (too hot); animals (birds, squirrels, and bugs); uneven ground surfaces; noise from passing cars and from teachers, students, friends, and peers walking through and around the space without regard for the instruction that was occurring. Although most people would consider these distractions to be small, individuals with ASD can become easily distracted and struggle with set shifting, or the ability to shift their attention from one task to the next (Yerys et al., 2015). Frequently, participants had to be redirected verbally by the teacher because of these distractions.

\section{Discussion}

Using multiple methods of data does not duplicate data, but compliments and enriches the sharing of a child's experience (Darbyshire, MacDougall, $\&$ Schiller, 2005). This study used a drawing, an observation, and a semi-structured interview to understand how children with ASD experience APE and how they may or may not transfer the skills learned in this setting into other settings with family or peers.

Drawings are a medium for participants to express their feelings and perceptions on a topic or situation. 
Drawings have been used successfully with children without disabilities to express their perception of the environment regarding movement opportunities at home and school (Hume, Salmon, \& Ball, 2005). Individuals diagnosed with ASD have been shown to have problems with memory (Goddar, Dritschel, \& Howling, 2014; Seese, Maske, Lynch, \& Gall, 2014), but they have also demonstrated that they can draw coherently and contextually (Happé \& Frith, 2006). Individuals with ASD have also shown the ability to express emotions, such as happiness or sadness, in their drawings similar to those of their peers (Jolley, O'Kelly, Barlow, \& Jarrold, 2013). Using the prompt: "draw me a picture of what your APE class with teacher _ is like for you" each of the participates in the study were able to hone in on one or more parts of their experience in an APE service, and draw that experience without prompting.

Participants commented frequently that the environment was hot and bright and that they needed breaks to drink water, sit, and cool down. These stops affect the amount of time that individuals with ASD receive their APE service. In a meta-analysis of interventions designed to increase moderate to vigorous activity levels in PE, Lonsdale et al. (2013) found that students needed to increase their time spent at this activity level to increase health benefits. Having too many distractions or sensory concerns causes breaks in engagement in physical activity. As APE is a sub discipline of PE, having fewer distractors and higher levels of engagement in physical activity is as important for individuals with disabilities as it is for their typically developed peers. Creating a space that is dedicated to APE in a school setting may be one way to mitigate these distractions. During observations, 7 of the 10 participants APE class was held outside on the blacktop in an open environment. Passing classmates, teachers, and campus guests all had access to the space of the participants. Peers frequently walked through the activities, saying "hi" and watching what was taking place. Though increasing peer interactions are positive, when not done in a meaningful way, it can be a distraction to instruction.

Providing dedicated space could also improve sensory needs that were commented on by the participants and improve sensory concerns that were observed by the researcher. The temperature was a complaint by several of the participants. If a dedicated space for APE could be made, this would allow for a potentially more controlled environment. Also, as participant 1 pointed out, being away from florescent lights is helpful. Working in a space that has dimmer lighting or lighting that was specific to the needs of kids with ASD could also help improve the environment for these children.

Qi and Ha (2012) found that stakeholders in physical education believe in the philosophical idea of inclusion in physical education, but differ in their ideas about how this can occur. Allowing children with ASD to share their experiences in APE will increase awareness of programing issues that may arise for this population and allow educators to consider this perspective when improving curriculum to create a more inclusive environment for all students. Similar to this study, Healey et al. (2013) also found that children with ASD expressed sensory issues - specifically a sensitivity to heat. Studies have also found physical activity improves behavior in the classroom (Nicholson, Kehle, Bray, \& Heest, 2011; Todd \& Reid, 2006). Though participants in this study did not comment on improved classroom behavior because of their experiences in physical education, the participants reported that they enjoyed their time in their physical activity class. This positive behavior and demeanor that was both shared by the participants and observed by the researcher is an example of how movement experiences can be positive for children with ASD.

Finally, PE and APE teachers can have a huge influence on the experiences of their students in these settings. Every participant in the study spoke positively about their APE teachers. APE teachers in California are held to high standards (Adapted Physical Education Guidelines in California Schools, 2012) and in California, must be "highly qualified" as defined by the No Child Left Behind Act (2012). The experience and education of these teachers provide them with the tools necessary to make APE services safe and appropriate for the children they are serving. One could argue that the high level of training that these teachers receive, makes the experience of the children they serve more positive than less qualified services other teachers may offer. Qi and Ha (2012) found that stakeholders in physical education believe in the philosophical idea of inclusion in physical education, but differ in their ideas about how this can occur. Allowing children with ASD to share their experiences in APE will increase awareness of programing issues that may arise for this population and allow educators to consider this perspective when improving curriculum to create a more inclusive environment for all students.

\section{Barriers and Facilitators}

Obrusnikova and Cavalier (2011) identified perceived barriers and facilitators to afterschool physical activity 
for individuals with ASD: intrapersonal, interpersonal and environmental. This study found similar barriers and facilitators as to how individuals with ASD perceived their APE experience. Intrapersonal barriers and facilitators are influenced by an individual's characteristics and how they respond to the environment and individuals around them (Bardus, Blake, Lloyd, \& Suggs, 2014). It reflects an individual's internal beliefs. This factor was seen in the participants' perceptions of the APE activities they participated in and how they viewed the importance of physical activity. Participants shared that they knew physical activity was important because they believed it made them healthy. They also shared that exercise was good for their body. Obrusnikova and Cavalier (2011) identified peers and family members (interpersonal) as major influences on after-school activities for individuals with ASD. The present study found similar influences for the participants' use of skills learned in APE in other settings, both in school (recess) and after school. Participants in this shared through their semi-structured interviews that parents, siblings, and peers all influenced their participation regarding use of skills learned in APE in other environments. As discussed previously, the environment was helpful for some participants and a facilitator for others. For example, participant 1 liked APE because it was a break from the fluorescent lights. Participant 4 commented that she wished that either she could swim all the time for PE or that she could run laps in the sprinklers so that she could be cooler. The environmental barrier of weather was specifically identified in both studies. As can be seen in the current and previous studies, there are a variety of internal and external forces that interact on an individual with ASD to influence participation in physical activity whether in a school or after school setting.

\section{Limitations}

There are some limitations to the current study that should be noted and improved upon in later research of this kind. Participants in this study had narrative retell capabilities of at least a second-grade level; the experiences of children with ASD receiving APE who have lower language capabilities or who are nonverbal were not addressed. Additionally, participants were asked to draw about their APE class in a general way. This question is vague and may have allowed participants to focus only on a good day or only on a bad day in their class. Future research should collect data over a period of time, perhaps across a month, term or school year to see if there are changes in the perceptions of the students.

To add to the validity of the study, questions were followed in the order that they were written. However, because of the individuality and the spectrum of individuals who have ASD, at times, more probes or a different question order would have gathered more information. Whereas typically developed children may have shared more information in the semi-structured interviews, the participants in this study, who had ASD, would sometimes only provide direct and concise answers to questions. Although the interview questions were detailed and had been reviewed by experts in the field for content, they were limited in the information that they were able to capture. The aim of this study was to focus on the voices of the children with ASD. Future research should work to include their perspective as part of the experience of all the stakeholders - parents, APE teachers, PE teachers, special education teachers, peers and/or general education teachers.

The order and timing of the data collected may also be a limiting factor. All data were collected over a two-week period for each participant. The data were collected in the order of picture, observation and semi-structured interview. It can be argued that the timing of the picture at the beginning of the study may have captured less detail of what was occurring in the APE setting than if it would have occurred at the same time as the semi-structured interview or immediately following the APE observation. Though it did not seem the case for the researcher in this study, children with ASD can be very literal in their thought process, causing a disconnect from what they are drawing and what they are being asked to describe. The same could be said regarding the semi-structured interview and that participants may have had more to share about their experience if the interview was timed to take place immediately following the APE class so that the concepts of what were being asked were more concrete. Finally, each type of data - drawing, observation and interview - were collected once for each participant in a short period of time. This limits the amount of information that was gathered from the participants and could have predisposed the data to having a positive or negative if the participant was having a positive or negative experience in APE during this snapshot of time. Recommendations for future research include larger studies with mixed method designs and focus groups at multiple sites to garner the perspective of more individuals. 


\section{Perspective}

This study will conclude with a comment from one of the participants. At the end of the interview, participant 7 stated, "You know, it is really nice to have someone ask me what I thought." Many of the children showed signs of disbelief and excitement during every aspect of this study, beginning with being asked their permission and their opinion in the signing of the assent forms, through to the end of the study, when asked to member check their interviews.

Furthermore, this study has shown that a sample of children with ASD had shared experiences in APE and the translation of these skills into other environments. This shared experience of individuals with ASD in APE has never been examined and, as such, adds to the body of knowledge in this newly developing area of research. Learning the barriers and facilitators to any individual's participation in a positive behavior is important. It is important in all settings to better identify these factors for populations that, historically, have been thought of as incapable of sharing their experiences.

\section{References}

Adapted Physical Education Guidelines in California School. (2012). California State Council on Adapted Physical Education. Retrieved from http://www.califstatecouncilape.org/ california-ape-guidelines.html

American Psychiatric Association. (2013). Diagnostic and statistical manual of mental disorders (5th ed.). Arlington, VA: American Psychiatric Publishing.

Bardus, M., Blake, H., Lloyd, S., \& Suggs, S. L. (2014). Reasons for participating and not participating in an e-health workplace physical activity intervention: A qualitative analysis. International Journal of Workplace Health Management, 7(4), 229-246. doi:10.1108/IJWHM-11-2013-0040

Bronfenbrenner, U. (1977). Toward an experimental ecology of human development. American Psychologist, 32(7), 513-531. doi:10.1037/0003-066X.32.7.513

Carter, M., Stephenson, J., Clark, T., Costley, D., Martin, J., Williams, K., Browne, L., ... Bruck, S. (2014). Perspectives on regular and support class placement and factors that contribute to success of inclusion for children with ASD. Journal of International Special Needs Education, 17(2), 60-69. doi: http://dx.doi.org/10.9782/2159-4341-17.2.60

Centers for Disease Control and Prevention. (2015). Autism spectrum disorder. Retrieved from http://www.cdc.gov/ ncbddd/autism/data.html

Cook, J. L., Blakemore, S. J., \& Press, C. (2013). Atypical basic movement kinematics in autism spectrum conditions. Brain, 136(9), 2816-2824. doi:10.1093/brain/awt208

Darbyshire, P., MacDougall, C., \& Schiller, W. (2005). Multiple methods in qualitative research with children: more insight or just more? Qualitative Research, 5(4), 417-436. doi:10.1177/1468794105056921
Ding, D. (2004). Ecological models: Application to physical activity. Encyclopedia of Health and Behavior, 1, 288-291. doi: http://link.springer.com/referenceworkentry /10.1007\%2F978-1-4419-1005-9_1125

Fleischmann, A. (2012). Carly's voice: Breaking through Autism. New York, New York. Simon and Schuster.

Goddard, L., Dritschel, B., \& Howlin, P. (2014). A preliminary study of gender differences in autobiographical memory in children with an autism spectrum disorder. Journal of Autism and Developmental Disorders, 44(9), 2087-2095. doi:10.1007/s10803-014-2109-7

Grandin, T. (2011). The way I see it: A personal look at autism and Asperger 's. Arlington, TX: Future Horizons.

Grinker, R. R. (2015, May). Who owns autism? Exceptionalism, stigma, and stakeholders. Paper presented as Keynote Address at the International Meeting for Autism Research, Little America Hotel, Salt Lake City, UT.

Gyurcsik, N. C., Spink, K. S., Bray, S. R., Chad, K., \& Kwan, M. (2006). An ecologically based examination of barriers to physical activity in students from grade seven through first-year university. Journal of Adolescent Health, 38(6), 704-711. doi:10.1016/j.jadohealth.2005.06.007

Hammersley, M. (2004). Phenomenology. In M. Lewis-Beck, A. Bryman, \& T. Liao (Eds.), Encyclopedia of social science research methods (pp. 816-817). Thousand Oaks, CA: Sage. doi:10.4135/9781412950589.n708

Happé, F., \& Frith, U. (2006). The weak coherence account: detail-focused cognitive style in autism spectrum disorders. Journal of Autism and Developmental Disorders, 36(1), 5-25. doi:10.1007/s10803-005-0039-0

Healy, S., Msetfi, R., \& Gallagher, S. (2013). "Happy and a bit Nervous": The experiences of children with autism in physical education. British Journal of Learning Disabilities, 41(3), 222-228. doi:10.1111/bld.12053

Higashida, N. (2013). The reason I jump: The inner voice of a thirteen-year-old boy with autism. New York, NY. Random House.

Hume, C., Salmon, J., \& Ball, K. (2005). Children's perceptions of their home and neighborhood environments, and their association with objectively measured physical activity: a qualitative and quantitative study. Health Education Research, 20(1), 1-13. doi:10.1093/her/cyg095

Humphrey, N., \& Lewis, S. (2008). What does "inclusion" mean for pupils on the autistic spectrum in mainstream secondary schools? Journal of Research in Special Educational Needs, 8(3), 132-140. doi:10.1111/j.1471-3802.2008.00115.x

Huws, J., \& Jones, R. (2008). Diagnosis, disclosure, and having autism: An interpretative phenomenological analysis of the perceptions of young people with autism. Journal of Intellectual and Developmental Disability, 33(2), 99-107 doi:10.1080/13668250802010394

Jolley, R. P., O'Kelly, R., Barlow, C. M., \& Jarrold, C. (2013). Expressive drawing ability in children with autism. British Journal of Developmental Psychology, 31(1), 143-149. doi:10.1111/bjdp.12008

Kalvaitis, D., \& Monhardt, R. M. (2012). The architecture of children's relationships with nature: a phenomenographic investigation seen through drawings and written narratives of elementary students. Environmental Education Research, 18(2), 209-227. Retrieved from: http://dx.doi.org/10.1080/1 3504622.2011 .598227 
Kana, R. K., Libero, L. E., Hu, C. P., Deshpande, H. D., \& Colburn, J. S. (2014). Functional brain networks and white matter underlying theory-of-mind in autism. Social Cognitive and Affective Neuroscience, 9(1), 98-105. doi:10.1093/ scan/nss 106

Libertus, K., Sheperd, K. A., Ross, S. W., \& Landa, R. J. (2014). Limited fine motor and grasping skills in 6-monthold infants at high risk for autism. Child development, 85(6), 2218-2231. doi:10.1111/cdev.12262

Lonsdale, C., Rosenkranz, R. R., Peralta, L. R., Bennie, A., Fahey, P., \& Lubans, D. R. (2013). A systematic review and meta-analysis of interventions designed to increase moderate-to-vigorous physical activity in school physical education lessons. Preventive Medicine, 56(2), 152-161. doi:10.1016/j.ypmed.2012.12.004

Loukusa, S., Mäkinen, L., Kussikko-Gauffin, S., Ebeling, H., \& Moilanen, I. (2014). Theory of mind and emotion recognition skills in children with specific language impairment, autism spectrum disorder and typical development: group differences and connection to knowledge of grammatical morphology, word-finding abilities and verbal working memory. Internation Journal of Language \& Communication disorders, 49(4), 498-507. doi:10.1111/1460-6984.12091

McKenzie, T. L. (2002). Use of direct observation to assess physical activity. Physical activity assessments for health-related research. Champaign, IL: Human Kinetics, 179-195.

Miles, M. B., Huberman, A. M., \& Saldana, J. (2013). Qualitative data analysis: A methods sourcebook. Thousand Oaks, CA: Sage.

Moran, J. M., Young, L. L., Saxe, R., Lee, S. M., O‘Young, D., Mavros, P. L., \& Gabrieli, J. D. (2011). Impaired theory of mind for moral judgment in high-functioning autism. Proceedings of the National Academy of Sciences, 108(7), 2688-2692. Retrieved from: http://www.pnas.org/content/108/7/2688.short

Nicholson, H., Kehle, T. J., Bray, M. A., \& Heest, J. V. (2011). The effects of antecedent physical activity on the academic engagement of children with autism spectrum disorder. Psychology in the Schools, 48(2), 198-213. doi:10.1002/ pits. 20537

No Child Left Behind Act of 2001, Qualification for teachers and paraprofessionals, 20 U.S.C. $§ 6319$ (2012).

Obrusnikova, I., \& Cavalier, A. (2011). Perceived barriers and facilitators of participation in after-school physical activity by children with autism spectrum disorders. Journal of Developmental and Physical Disabilities, 23(3), 195-211. doi:10.1007/s10882-010-9215-z

Pitney, W., \& Parker, J. (2009). Qualitative research in physical activity and the health professions. Champagne, IL: Human Kinetics.

Prince-Hughes, D. (2004). Songs of the gorilla nation: My journey through autism. New York, NY: Crown.

Qi, J., \& Ha, A. S. (2012). Inclusion in physical education: A review of literature. International Journal of Disability, Development and Education, 59(3), 257-281. doi:10.1080/ 1034912X.2012.697737

Robison, J. E. (2008). Look me in the eye: My life with Asperger's. New York, NY: Random House.

Robison, J. (2015, May). The lived experience of autism. Paper presented at the International Meeting for Autism Research, Salt Lake City, UT.
Saldana, J. (2015). The coding manual for qualitative researchers. Thousand Oaks, CA: Sage.

Schurink, J., Hartman, E., Scherder, E. J. A., Houwen, S., \& Visscher, C. (2012). Relationship between motor and executive functioning in children with pervasive developmental disorder not otherwise specified. Research in Autism Spectrum Disorders, 6(2), 726-732. doi:10.1016/j. rasd.2011.10.013

Schultz, T. R., Sreckovic, M. A., Able, H., \& White, T. (2016). Parent-Teacher Collaboration: Teacher Perceptions of What is Needed to Support Students with ASD in the Inclusive Classroom. Education and Training in Autism and Developmental Disabilities, 51(4), 344. Retrieved from: http://search. proquest.com/openview/6e4cd569197be2a85e65183f712ade24/1?pq-origsite $=$ gscholar \&cbl $=2032023$

Seese, R. R., Maske, A. R., Lynch, G., \& Gall, C. M. (2014). Long-term memory deficits are associated with elevated synaptic ERK1/2 activation and reversed by mGluR5 antagonism in an animal model of autism. Neuropsychopharmacology, 39(7), 1664-1673. doi:10.1038/npp.2014.13

Smith, J., Flowers, P., \& Larkin, M. (2009). Interpretative phenomenological analysis: Theory, method and research. Thousand Oaks, CA: Sage.

Solomon, O. (2015, May). Emic and etic perspectives in the construction of authoritative knowledge on autism. Paper presented at the International Meeting for Autism Research, Salt Lake City, UT.

Spencer, D. \& Pearson, T. (2012). Test of Narrative Retell. Laramie, WY: Language Dynamics Group.

Syriopoulou-Delli, C. K., Cassimos, D. C., \& Polychronopoulou, S. A. (2016). Collaboration between teachers and parents of children with ASD on issues of education. Research in developmental disabilities, 55, 330-345. doi: 10.1016/j. ridd.2016.04.011

Tammet, D. (2007). Born on a blue day: Inside the extraordinary mind of an autistic savant. New York, NY: Simon and Schuster.

Thomas, E., \& Magilvy, J. K. (2011). Qualitative rigor or research validity in qualitative research. Journal for Specialists in Pediatric Nursing, 16(2), 151-155. doi:10.1111/j.1744-6155.2011.00283.x

Todd, T., \& Reid, G. (2006). Increasing physical activity in individuals with autism. Focus on Autism and Other Developmental Disabilities, 21(3), 167-176. Retrieved from http://foa.sagepub.com/

Whyatt, C., \& Craig, C. M. (2013). Interceptive skills in children aged 9-11 years, diagnosed with autism spectrum disorder. Research in Autism Spectrum Disorders, 7(5), 613-623. Retrieved from http://sfxhosted.exlibrisgroup.com/

Williams, D. (2007). Nobody nowhere: The extraordinary autobiography of an autistic. London, England: Kingsley.

Yerys, B. E., Antezana, L., Weinblatt, R., Jankowski, K. F., Strang, J., Vaidya, C. J., \& Kenworthy, L. (2015). Neural correlates of set-shifting in children with autism. Autism Research, 8(4), 386-397. doi:10.1002/aur.1454

\section{Corresponding author}

Josephine Blagrave

Email address | ablagrave@csuchico.edu 